\title{
GRAPHICAL TECHNIQUES IN DEBIASING: AN EXPLORATORY STUDY
}

\author{
by \\ S. Bhasker \\ Information Systems Department \\ Leonard N. Stern School of Business \\ New York University \\ New York, New York 10006 \\ and
}

\section{A. Kumaraswamy}

Management Department

Leonard N. Stern School of Business

New York University

New York, NY 10006

October, 1990

Center for Research on Information Systems

Information Systems Department

Leonard N. Stern School of Business

New York University

\section{Working Paper Series}

STERN IS-90-19

Forthcoming in the Proceedings of the 1991 Hawaii International

Conference on System Sciences 


\begin{abstract}
Base rate and conjunction fallacies are consistent biases that influence decision making involving probability judgments. We develop simple graphical techniques and test their efficacy in correcting for these biases. Preliminary results suggest that graphical techniques help to overcome these biases and improve decision making. We examine the implications of incorporating these simple techniques in Executive Information Systems.
\end{abstract}

\title{
Introduction
}

Today, senior executives operate in highly uncertain environments. They have to collect, process and analyze a deluge of information - most of it ambiguous. But, their limited information acquiring and processing capabilities constrain them in this task [25]. Increasingly, executives rely on executive information/support systems for various purposes like strategic scanning of their business environments, internal monitoring of their businesses, analysis of data available from various internal and external sources, and communications $[5,19,32]$.

However, executive information systems are, at best, support tools. Executives still rely on their mental or cognitive models of their businesses and environments and develop heuristics to simplify decision problems [10,16,25]. Specifically, to evaluate compound events and conditional probabilities, they tend to use similarity of an event to a relevant model (representativeness), ease of recall (availability), and sequential adjustment from an initial reference value (anchoring \& adjustment) [26]. These simple rules, in turn, bias their judgment and result in consistent errors and wrong decisions. 
Little work has been devoted to debiasing despite the serious impact of biases on probability judgments and executive decision making. In this exploratory study, we strive to control the effects of two judgmental errors commonly attributed to representativeness bias: the base rate fallacy and the conjunction fallacy [14,29]. Keeping in mind the pervasive impact of executive information systems in influencing the mental models of executives [21] and the ease of implementation of graphical techniques in such systems, we design and test the efficacy of graphical debiasing techniques in correcting for the two fallacies. Finally, we examine the implications of our results for EIS and executive decision making.

\section{Prior Research}

\section{Base Rate Fallacy}

This is the tendency of even mathematically "sophisticated" people to disregard base rates (prior probabilities) of events while making conditional probability judgments. This occurs when people feel that the base rate information is not salient to the decision problem [20]. People use base rates only when the base rates have a causal connotation to the event [30] or when they seem to be more relevant/specific to the event than other given information $[1,3,9]$. Otherwise, only experience and feedback to people over time can prompt routine usage of base rates in conditional probability judgments [3].

\section{Conjunction Fallacy}

This is a tendency of people to judge the occurrence of a conjunction of two events to be more likely than the occurrence of either of those events. People use representativeness of an event to a relevant model to assess its probability and because "the representativeness of 
an event can be increased by specificity, a compound target can be judged more probable than one of its components" [29]. People use extensional (consistent with probability theory) reasoning only when they are cued by modifying the problem statement to calculate relative frequencies of constituent events before estimating that of the conjunction [28].

\section{Debiasing}

Debiasing involves nullifying the influence of a bias and improving the quality of judgments and decisions. Fischhoff [7] talks of some techniques for debiasing and reviews efforts to reduce hindsight bias and overconfidence.

Fong, Krantz and Nisbett [8] successfully trained subjects to use the law of large numbers to solve everyday problems associated with its use. But, statistical training has limited application while dealing with complex concepts unless people possess basic knowledge of probability theory.

To overcome conjunction fallacy, Tversky \& Kahneman [28] used different textual presentations of the problem statement to cue people along the desired decision path.

Bar-Hillel [2] and Schocken [24] outline the possible use of graphical representation of information to control for base rate fallacy. Their simple graphical methods would facilitate debiasing by cueing people to use base rates. However, their suggestions, to our knowledge, have not been implemented or empirically tested.

\section{Graphical Techniques for Debiasing}

Executives make decisions based on relevant information made available to them. The complex interaction of task demands, presentation format and decision maker's knowledge 
influence the final strategy adopted [12,15] and therefore presentation of relevant information that controls for biases becomes exceedingly important.

The importance of information displays for effective decision making $[6,11,31]$ has propelled a much research on displays (refer [15]). Information presentation and display have important cognitive implications [15,22,27]. Larkin \& Simon [17] studied the relative merits of three informationally equivalent representations - propositional, sentential and pictorial. They concluded that pictorial representations are computationally more efficient because they greatly reduced the cognitive effort to search and solve problems by providing salient information simply.

Specifically, studies indicate that both tabular and graphical presentation formats aid decision making whenever congruence exists between task demands and the format used $[4,12,15,23]$. In view of this encouraging support for pictorial representation formats, we chose to explore the debiasing capabilities of graphical formats.

\section{Description of Our Graphical Techniques}

Base rate fallacy (Figure 1a). We convert probabilities to percentages in the population of interest and represent the entire population by a rectangle. Then, we represent base rates by shading appropriately scaled portions of this rectangle. Finally, we superimpose likelihood to get conditional probability.

For example in Problem 1 (see Appendix A for problems), the total number of cabs in the city is represented by a rectangle. The base rates of Green (15\%) and Blue cabs $(85 \%)$ are represented by shading appropriately scaled portions of the rectangle using respective colors. Then, the likelihood (reliability of witness $=80 \%$ ) is superimposed 


\section{FIGURE 1 \\ ILLUSTRATION OF OUR TECHNIQUE}
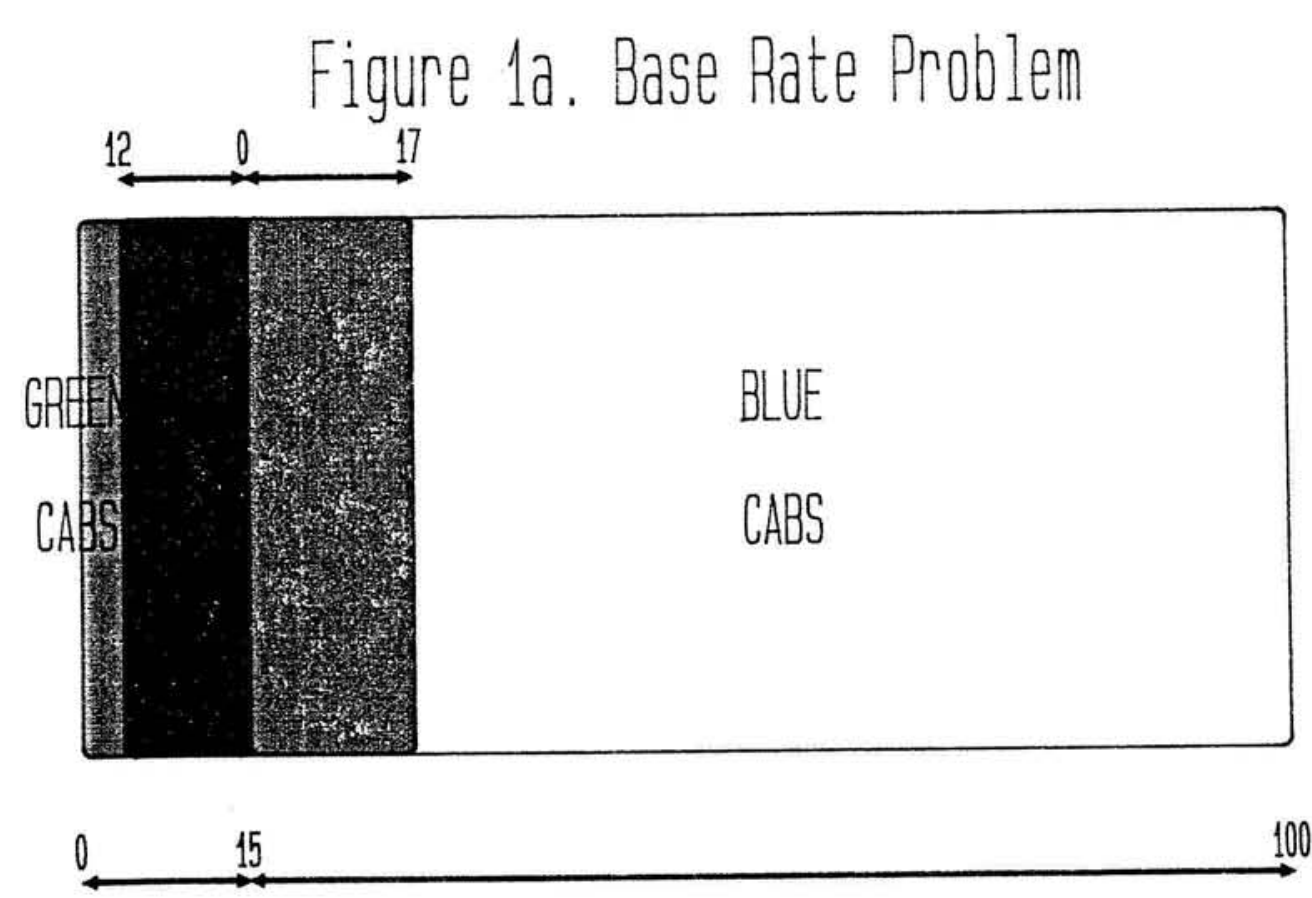

Figure 1b. Conjunction Problem

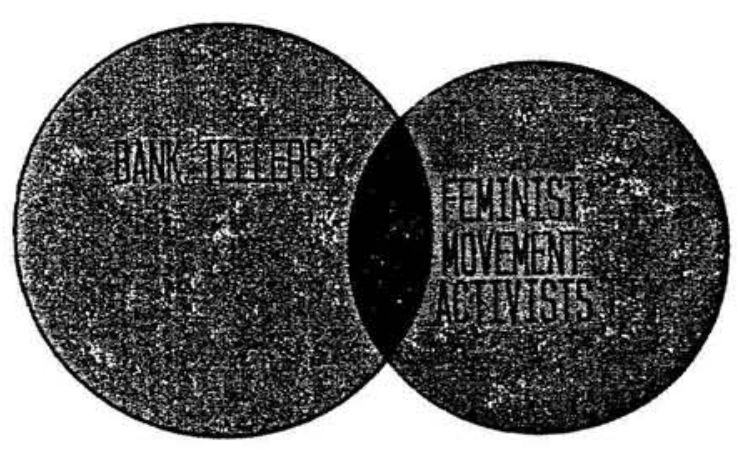


(denoted by the darkly shaded portion). Evidently the probability of the witness being wrong is greater as the probability that the car was blue is greater than probability that the car was green (dark, hatched portion). Also, it is easy to understand conditional probabilities as percentages by reading them directly from the graph.

Conjunction fallacy (Figure 1b). Here, we use Venn diagrams. We represent the entire population as a rectangle and denote the populations of interest by circles of different colors. Then, we represent conjunction by the overlap of these circles.

For example in Problem 6, the event that Linda is a bank teller and the event that she is an activist in the feminist movement are represented respectively by two circles. Then, the conjunction - that Linda is both a bank teller and an activist - is denoted by the overlap of the two circles (dark, hatched portion). It is immediately evident that the overlap between the two circles cannot be greater than either of the circles. Or, the probability of occurrence of the conjunction of any two events cannot be greater than the probability of occurrence of either constituent event.

\section{Methodology}

We conducted experiments with undergraduate business students (who lacked prior exposure to probability and statistics) as subjects. Students were informed that the experiment involved decision making and that participation was voluntary. No incentive was provided. Students were assured that their anonymity would be preserved and their performance in these experiments would not affect their grades in any way.

We used charts to illustrate our graphical techniques. Given the exploratory nature of our study, we were wary of making investments in computer displays at this stage. Computer displays could be used later in a more rigorous study if results were promising. 


\section{Figure $2 a$ Comparison of Probability Responses to Problem 1 (Base Rate)}

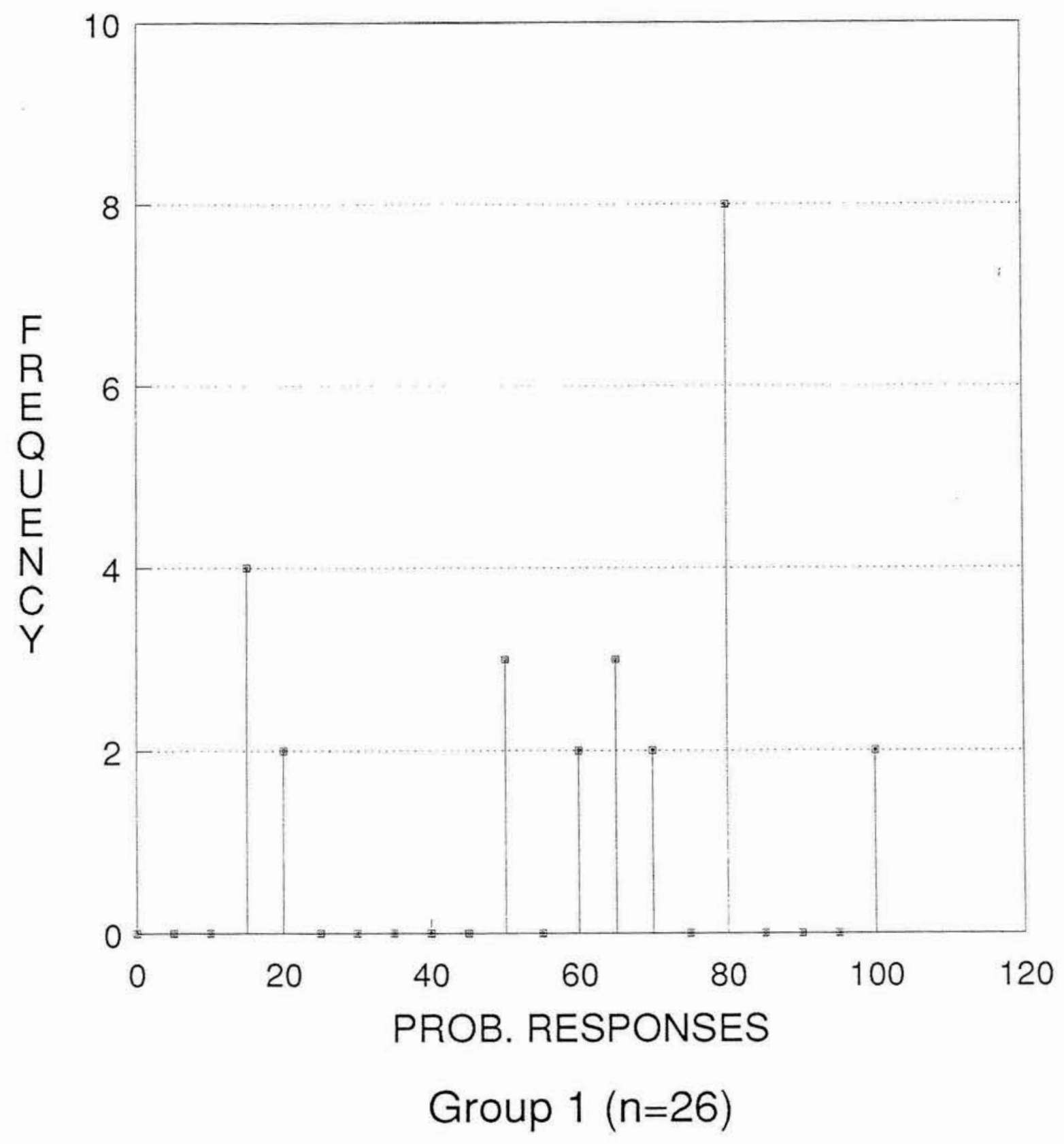




\section{Figure 2b. \\ Comparison of Probability Responses to Problem 1 (Base Rate)}

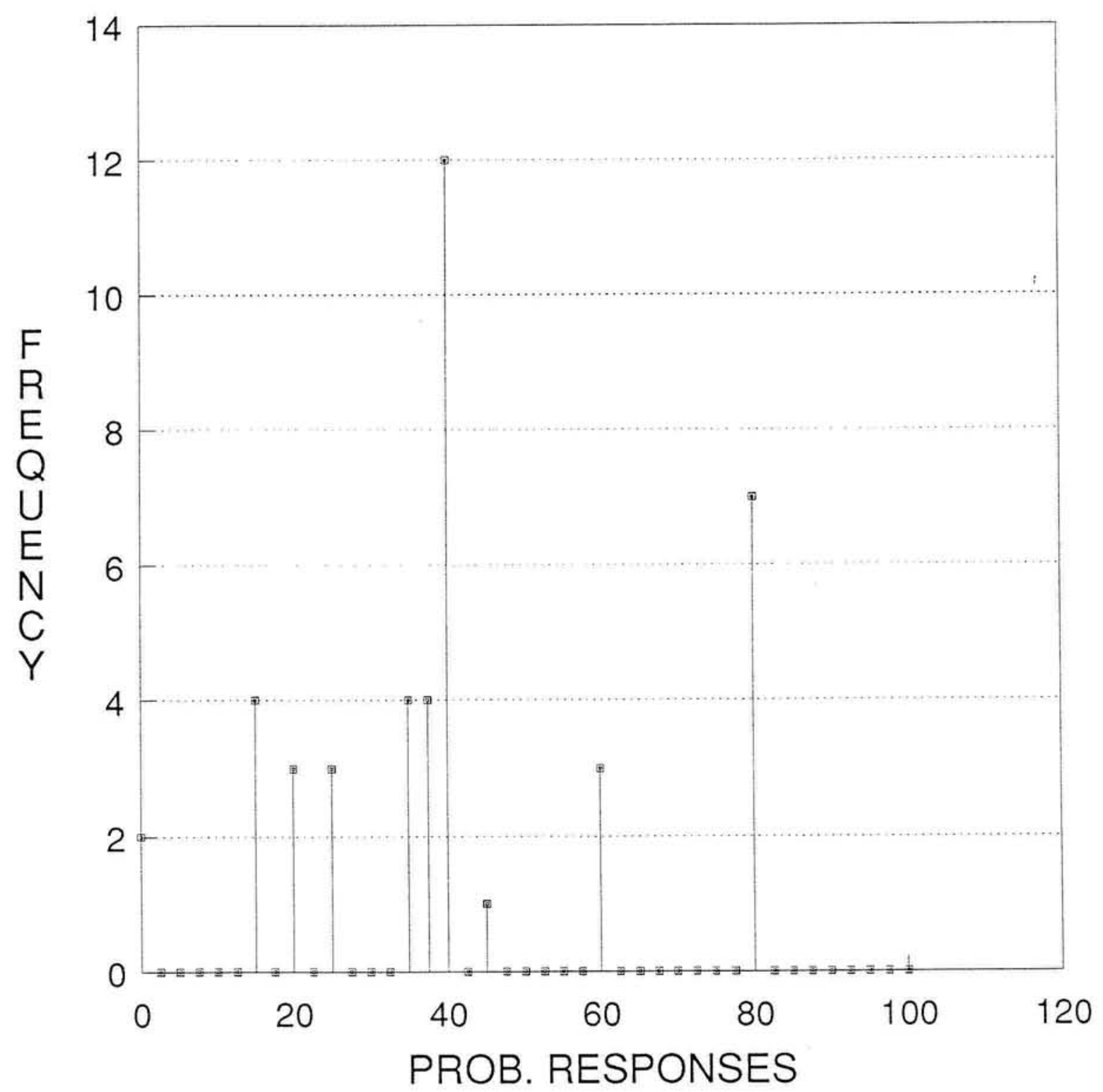

Group $2(n=43)$ 
We used a one-control-group, one-experimental-group design. Group 1 subjects $(n=26)$ served as control and were given two questions in sequence: Problem 1, a base rate type problem, followed by Problem 2, a conjunction type problem. They were asked to answer these questions using their intuition.

Group 2 subjects $(n=43)$ were given the treatment. First, they were shown our graphical technique to solve Problem 3, a base rate problem (see Appendix B for actual chart formats). Then, they were given Problem 1 and asked to solve it using the graphical technique. Next, they were shown how to solve Problem 4, a conjunction type problem. Subsequently, they were asked to solve Problem 2 using the same technique.

The distribution of probability responses to Problem 1 is summarized in Figures 2a \& 2b. Group 1 (control) exhibited base rate fallacy with probability estimates close to $80 \%$. Also, there were no responses near $41 \%$, the correct value. However, Group 2 subjects used base rates better with 21 out of 43 subjects estimating the probability to be between $35 \%$ and-45\%. While 12 subjects answered correctly (41\%), only 6 still estimated the probability as $80 \%$.

Thus, the use of graphical technique reduced the effect of representativeness bias considerably for base rate type problems.

Responses to Problem 2 are given in Table 1. Surprisingly, both Group 1 and Group 2 subjects exhibited conjunction fallacy. Seemingly, our graphical technique had not helped overcome conjunction bias. Either the subjects had not found this technique relevant, or they had not established the link between the use of the technique to solve Problem 4 , a simple conjunction type problem, and Problem 2 that is complicated further by representativeness considerations. 
Table 1

Comparison of Responses to Problem 2 for Groups $1 \& 2$ (Conjunction)

\begin{tabular}{lcc}
\hline & $\begin{array}{c}\text { Group 1 } \\
(\mathrm{n}=26)\end{array}$ & $\begin{array}{c}\text { Group 2 } \\
(\mathrm{n}=43)\end{array}$ \\
& $84.5 \%$ & $86 \%$ \\
Violation & & \\
& & \\
$\begin{array}{l}\text { Avg. Rank: } \\
\text { 1) Active in Fem. } \\
\quad \text { movement }\end{array}$ & 2.12 & 2.02 \\
2) Bank Teller & 6.54 & 6.50 \\
3) Conjunction & 5.07 & 4.84 \\
\hline
\end{tabular}

Given the encouraging results for base rate fallacy, we figured that the complication introduced by representativeness in Problem 2 had prevented subjects from relating our graphical technique as a solution concept for this problem. To test whether this were indeed true, we introduced another stage in our study.

We used two groups - Group $3(n=18)$ and Group $4(n=47)$. Group 3 subjects were used to replicate Group 2 results with regard to conjunction fallacy. They were given the same treatment as Group 2 subjects. Then, they were asked to solve two problems using this technique: a simple conjunction type problem, Problem 5, and next Problem 2, a conjunction type problem that incorporated representativeness. Given our expectations, Group 3 subjects should have no problem in solving Problem 5; but they should exhibit conjunction fallacy in solving Problem 2.

Group 4 subjects were treated with the use of graphical technique to solve Problem 6 that involved representativeness. Then, they were asked to solve Problem 2 followed by 
Problem 5 (order reversed from Group 3). Here, we would expect the subjects' tendency to exhibit the conjunction fallacy to decrease considerably in solving both problems.

Group 3 and Group 4 results are given in Table 2 .

Table 2

Comparison of Responses to Problems $2 \& 5$

for Groups 3 \& 4 (Conjunction)

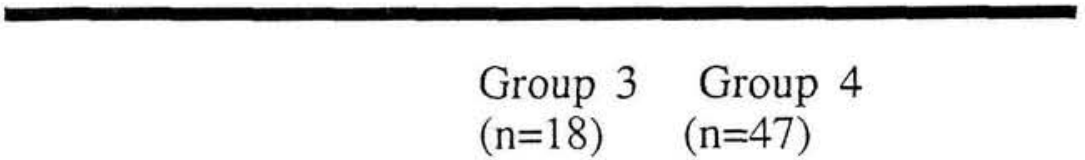

Problem 5

Violation

$17 \%$

$17 \%$

Avg. Rank:

1) Educated

1.2

1.1

2) Working

3) Conjunction

2.06

1.93

2.6

2.7

Problem 2

Violation

$83 \%$

$25 \%$

Avg. Rank:

1) Active in Fem. $\quad 1.83 \quad 1.44$ movement

2) Bank Teller

$6.41 \quad 6.11$

3) Conjunction

4.83

6.40

As expected, Group 3 results replicated our findings for Group 2. Also, for Group 4, violations of the conjunction rule for Problem 2 decreased dramatically. This lends credence to our view that subjects were unable to relate our graphical technique for a 
purely conjunction type problem as a means to solve conjunction type problem with representativeness considerations. But, when this connection was established by showing the subjects the use of this technique for such a problem (Problem 6), they used it effectively to arrive at the correct ordering for Problem 2. Thus, we can conclude that our graphical technique controls for conjunction bias also.

\section{Discussion and Implications}

Being an exploratory study, our main intention was to test whether graphical representation techniques were useful in controlling for these biases. Results suggest that graphical techniques are useful in controlling for representativeness bias while judging conditional probabilities and conjunction. Still, results remain to be validated across a larger sample consisting of both naive and sophisticated subjects.

It may be argued that business undergraduate subjects are naive (in the sense that they have no experience and exposure to decision making in the business world) and the results cannot be generalized to more sophisticated subjects like executives. Yet, even sophisticated subjects have been known to exhibit these biases $[13,26]$. Thus, there is a strong basis for applying this study to executives. We would argue that executives who have been exposed to pictorial representation in EIS would be more responsive to this treatment than "relatively naive" business undergraduate subjects.

Our exploratory study has only a limited scope. We have not ascertained whether subjects remember our techniques and use them to solve similar problems with passage of time. Also, we have not explored the moderating effects of instruction and learning in controlling for biases. These techniques can be implemented on computers and their 
efficacy in controlling for biases can be tested rigorously by generating hypotheses and testing them statistically for differences in the quality of responses (accuracy) and the time taken to solve real-life problems involving biases. A comprehensive study would require the following steps: (1) a pretest to check for biases and to measure decision making time; (2) treatment at various levels of support - (a) no support, i.e., neither graphics support nor instructions/training (b) only graphics support with no instruction or training (c) only instruction/training without graphics support (d) both graphics support and instruction/training; (3) a posttest to ascertain efficacy of support in terms of quality and quickness of decisions taken and a comparison of results for different levels of support; and (4) another posttest after a period for each level of support to check for retention of techniques.

If results support our position, implementation of these underlying ideas in EIS using graphical software packages is a simple task. Executives can use this as an option in a pull down menu. Thus, these simple decision aids will enable better quality of decisions by (1) presenting data in more meaningful formats and increasing their saliency; (2) improving analytical and modeling capabilities; and (3) enabling surfacing and testing fundamental assumptions and refining existing mental models [21]. These techniques are based on simple concepts like Venn diagrams and overlapping bar charts to which an executive already has ample exposure and do not require any special training or education.

Also, graphical techniques can be taught from an earlier stage at low cost in schools. Reinforcement of the use of such techniques even at a formative stage, with appropriate instruction, will result in their routine usage and a widespread reduction in the occurrence of biases across the population. 
The concepts of probability and statistics can be communicated in a simple way to decision makers by using such graphical representation techniques. Recent advances in computer graphics and research in information display formats and decision making hold great promise. All it needs now is less skepticism and more effort at development, testing and implementation of simple techniques in EIS to correct for biases in decision making.

\section{Acknowledgement}

We thank Professors Zur Shapira, Barry Floyd and Shimon Schocken, and anonymous reviewers at the Academy of Management and the Hawaii International Conference of System Sciences for their encouragement and constructive criticism. In particular, we thank Professor Shapira and an anonymous reviewer at HICSS for pointing out the moderating effects of instruction and learning and suggesting ways to account for them.

\section{References}

[1] M. Bar-Hillel, "The base rate fallacy in probability judgments," Acta Psychologica, Vol. 44, 1980, pp. 211-233.

[2] M. Bar-Hillel, Back to base rates. Paper presented at the symposium in memory of H. Einhorn, Chicago, 1988.

[3] M. Bar-Hillel \& B. Fischhoff, "When do base rates affect predictions?," Journal of Personality and Social Psychology, Vol. 41, 1981, pp. 671-680.

[4] I. Benbasat, A.S. Dexter \& P. Todd, "An experimental program investigating colorenhanced and graphical information presentation: An integration of the findings," 
Communications of the ACM, Vol. 29, 1986, pp. 1094-1105.

[5] R. L. Daft \& R. H. Lengel, "Information richness: A new approach to manager information processing and organization design," in B. Straw \& L. L. Cummings (eds.), Research in Organization Behavior, Greenwich, CT: JAI Press, 1984.

[6] G. DeSanctis, "Computer graphics as decision aids: Directions for research," Decision Sciences, Vol. 15, 1984, pp. 463-487.

[7] B. Fischhoff, "Debiasing," in D. Kahneman, P. Slovic \& A. Tversky (eds.), Judgement under Uncertainty: Heuristics and Biases, pp. 422-444. New York: Cambridge University Press, 1986.

[8] G. T. Fong, D. H. Krantz \& R. E. Nisbett, "The effect of statistical training on thinking about everyday problems," Cognitive Psychology, Vol 18, 1986, pp. 253292.

[9] Z. Ginosar \& Y. Trope, "The effects of base rates and individuating information on judgments about another person," Journal of Experimental Social Psychology, Vol 16, 1980, pp. 228-242.

[10] D. J. Isenberg, "How senior managers think," Harvard Business Review, Nov-Dec 1984, pp. 80-90.

[11] B. Ives, "Graphical user interfaces for business information systems," MIS Quarterly, Special Issue, 1982, pp. 211-244.

[12] S. L. Jarvenpaa, "The effect of task demands and graphical formats on information processing strategies," Management Science, Vol. 35, 1989, pp. 285-303.

[13] D. Kahneman. \& A. Tversky, "On prediction and judgement," ORI Research Monograph, Vol. 12(4), 1972. 
[14] D. Kahneman \& A. Tversky, "On the psychology of prediction," Psychological Review, Vol. 80, 1973, pp. 237-251.

[15] D. N. Kleinmuntz \& D. A. Schkade, "The cognitive implications of information displays in computer-supported decision making," Working paper No. 88/89-4-11, University of Texas, Austin, Texas, 1989.

[16] J. P. Kotter. "What effective general managers really do," Harvard Business Review, 60(6), Nov/Dec 1982, pp. 156-167.

[17] J. H. Larkin \& H. A. Simon, "Why a diagram is (sometimes) worth ten thousand words," Cognitive Science, Vol. 11, 1987, pp. 65-99.

[18] W. Mendenhall, R. Scheaffer \& D. Wackerly, Mathematical Statistics ' with Applications (3rd ed.), Boston: PWS Press, 1986.

[19] J. H. Moore, "Senior executive computer use," Unpublished Working Paper, Stanford Graduate School of Business, Palo Alto, California, 1986.

[20] R. Nisbett, E. Borgida, R. Crandall \& H. Reed, "Popular induction: Information is not necessarily informative," in D. Kahneman, P. Slovic \& A. Tversky (eds.), Judgement under Uncertainty: Heuristics and Biases, pp. 101-128. New York: Cambridge University Press, 1986.

[21] J. F. Rockart \& D. W. De Long, Executive Support Systems: The Emergence of Top Management Computer Use, Homewood,Il.: Dow Jones-Irwin, 1988.

[22] J. E. Russo, "The value of unit price information," Journal of Marketing, Vol. 14, 1977, pp. 193-201.

[23] Z. Shapira, "Making trade-offs between job attributes," Organizational Behavior and Human Performance, Vol. 28, 1981, pp. 331-355. 
[24] S. Schocken, "Biases and computer-based debiasing mechanisms: An experimental design for the case of representativeness," Unpublished working paper, University of Pennsylvania, Philadelphia, Penn., 1985.

[25]

H. A. Simon, "A behavioral model of rational choice," Quarterly Journal of Economics, Vol. 69, 1955, pp. 99-118.

[26] A. Tversky \& D. Kahneman, "Judgement under uncertainty: Heuristics and biases," Science, Vol. 185, 1974, pp. 1124-1131.

[27] A. Tversky \& D. Kahneman, "The framing of decisions and the psychology of choice," Science, Vol. 211, 1981, pp. 281-299.

[28] A. Tversky \& D. Kahneman, "Extensional versus intuitive reasoning: The conjunction fallacy in probability judgement," Psychological Review, Vol. 90, 1983, pp. 293-315.

[29] A. Tversky \& D. Kahneman, "Judgments of and by representativeness," in D. Kahneman, P. Slovic \& A. Tversky (eds.), Judgement under Uncertainty: Heuristics and Biases, pp. 84-98. New York: Cambridge University Press, 1986.

[30] A. Tversky \& D. Kahneman, "Causal schemas in judgments under uncertainty," in D. Kahneman, P. Slovic \& A. Tversky (eds.), Judgement under Uncertainty: Heuristics and Biases, pp. 117-128. New York: Cambridge University Press, 1986.

[31] W. Zachary, "A cognitively based functional taxonomy of decision support techniques," Human-Computer Interaction, Vol. 2, 1986, pp. 25-63.

[32] R. W. Zmud, "Supporting senior executives through decision support technologies: A review and directions for future research," in E. R. McLean \& H. G. Sol (eds.), Decision Support Systems: A Decade in Perspective, Amsterdam: Elsevier Science Publishers, 1986. 


\section{Appendix A}

Problem 1: [adapted from 13]

Two cab companies operate in a given city, the Blue and the Green (according to the color of the cab they run). Eighty five percent of the cabs are Blue, and the remaining $15 \%$ are Green.

A cab was involved in a hit-and-run accident at night.

A witness later identified the cab as a Green cab.

The court later tested the witness' ability to distinguish between Blue and Green cabs under night time visibility conditions. It found that the witness was able to identify each color correctly about $80 \%$ of the time, but confused it with the other color about $20 \%$ of the time.

1) Do you think the witness was right (Yes/ No)?

2) Roughly, what do you think are the chances that the errant cab was indeed Green, as claimed by the witness?

\section{Problem 2: [28]}

Given below is the personality sketch of a fictitious individual, Linda, followed by a set of occupations and avocations associated with her:

Linda is 31 years old, single, outspoken and very bright. She majored in Philosophy. As a student, she was deeply concerned with the issues of discrimination and social justice, and also participated in anti-nuclear demonstrations.

1) Linda is a teacher in elementary school.

2) Linda works in a bookstore and takes Yoga classes. 
3) Linda is active in feminist movement.

4) Linda is a psychiatric social worker.

5) Linda is a member of the League of Women Voters.

6) Linda is a bank teller.

7) Linda is an insurance salesperson.

8) Linda is a bank teller and is active in feminist movement.

Problem 3: [18]

A certain population of voters are $40 \%$ Republican and $60 \%$ Democrats. Of these, $70 \%$ Republicans and $30 \%$ Democrats support a certain issue. A person is selected at random. She supports the issue. Find the probability that she is a Democrat.

\section{Problem 4:}

100 students have registered in the Spring of 1989. Each student has taken at least one course of the 2 courses offered - Business Policy (BP) and Computers for Management (CIM).

70 students have taken Business Policy \& 60 have taken Computers for Management. How many students have taken both?

\section{Problem 5:}

There is a group of 100 women. All women in this group are either educated or working or both. 90 women are educated. 80 women are working. How many women are both educated and working? 
Rank in order the following statements on the number of women.

1) The number of women who are working; 2) The number of women who are both educated and working; 3) The number of women who are educated. ( 1 for maximum and 3 for minimum )

Problem 6: [adapted from 28]

Given below is a description of a person:

Bill is 34 years old. He is intelligent, but unimaginative, compulsive and generally lifeless.

In school, he was strong in mathematics but weak in social sciences and humanities.

Please rank the following statements by their probability:

1) Bill is a Sociologist.

2) Bill is an Accountant.

3) Bill is a Jazz player.

4) Bill is an Accountant and a Jazz player.

5) Bill is an Architect. 


\section{Appendix B}

\section{Chart Shown to Group 2 for Problem 3:}

Let the rectangle represent the total voters in the given area (Figure 3a).

As $40 \%$ are Republicans and $60 \%$ Democrats, let us divide the rectangle in the same proportion (Figure 3b).

We are also given that $70 \%$ of the Republicans support the issue and so do $30 \%$ of the Democrats. Let us represent the number of people that support the issue by a dark region (Figure 3c).

So, the percentage of Democrats who support the issue is $.3 \times .6=.18=18 \%$.

And, the percentage of Republicans who support the issue is $.4 \times .7=.28=28 \%$

The percentage of the total population who support the issue

$=(\%$ of Democrats who support the issue $)+(\%$ of Republicans who support the issue $)$

$=18 \%+28 \%=46 \%$

So, the probability that the person chosen is a Democrat

$=\{(\%$ of Democrats who support the issue $) /(\%$ of the total population who support the issue) $\} \times 100$

$=(18 / 46) \times 100=39 \%$

Thus, the probability that the person is a Democrat is less than $50 \%$ even though we have more Democrats than Republicans. 
Figure 3

Figure 3 a.

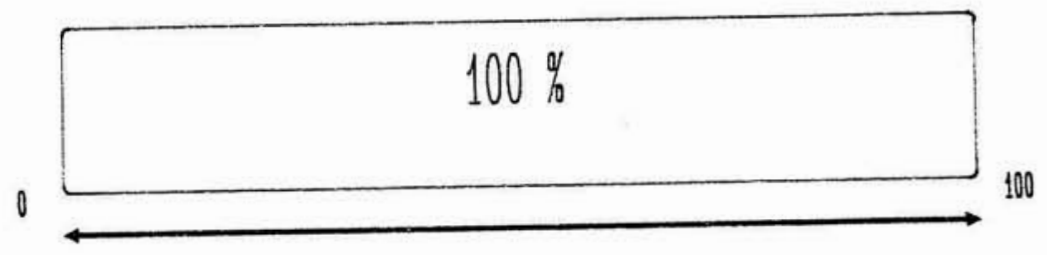

Figure $3 b$.

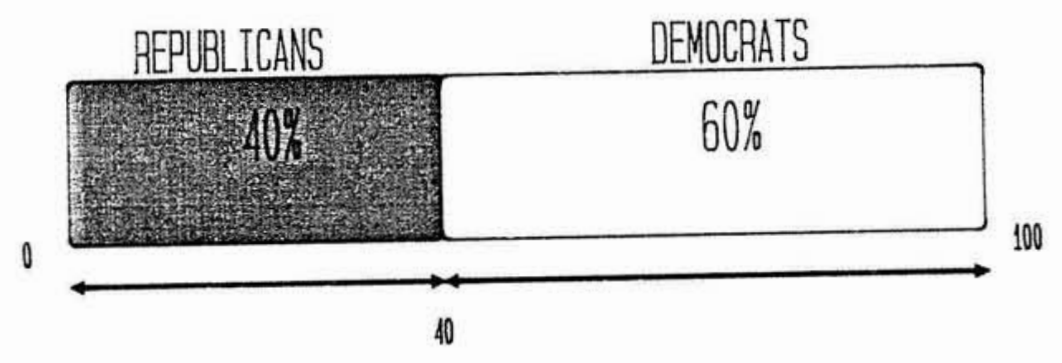

Figure 3C.

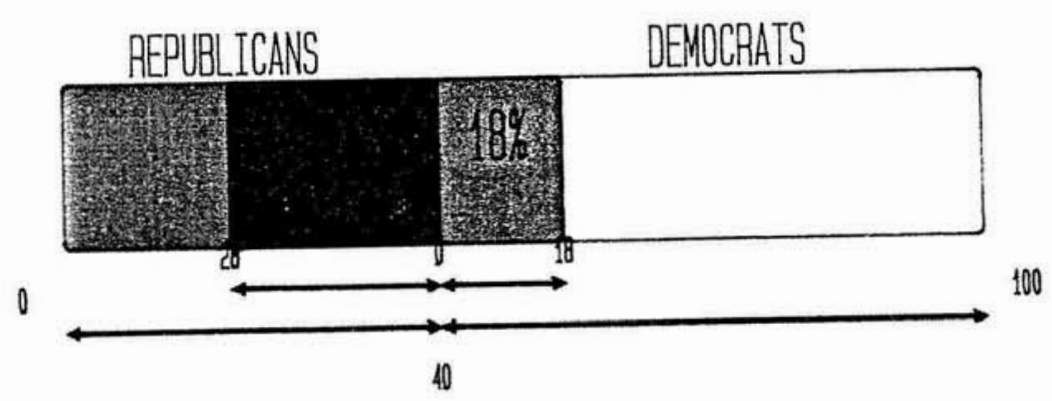




\section{Chart Shown to Group 2 and Group 3 for Problem 4:}

There are 100 students in a batch. Each student has taken atleast one course. Let this figure represent 100 students in the batch (Figure 4a).

70 students have taken BP (Figure 4b).

60 students have taken CIM (Figure 4c).

But, total number of students is 100 . So, some have taken both (Figure 4d).

Therefore, the number of students who have taken both are

$$
=(70+60)-100=130-100=30
$$

\section{Chart Shown to Group 4 for Problem 6:}

From the given description, Bill can be a Jazz player, an accountant or both. So, we need to consider only the following:

1) the group of all accountants.

2) the group of all jazz players (Figure 5a).

Bill can also belong to both groups at the same time (Figure $5 \mathrm{~b}$ ).

Now, we see the number of people belonging to both groups at the same time (darkly shaded region) is less than the number belonging to either group. In other words, the chance that Bill belongs to both groups at the same time is less than the chance that he belongs to either group.

So, the ordering will be such that statements $2 \& 3$ are always ranked before 4 . 


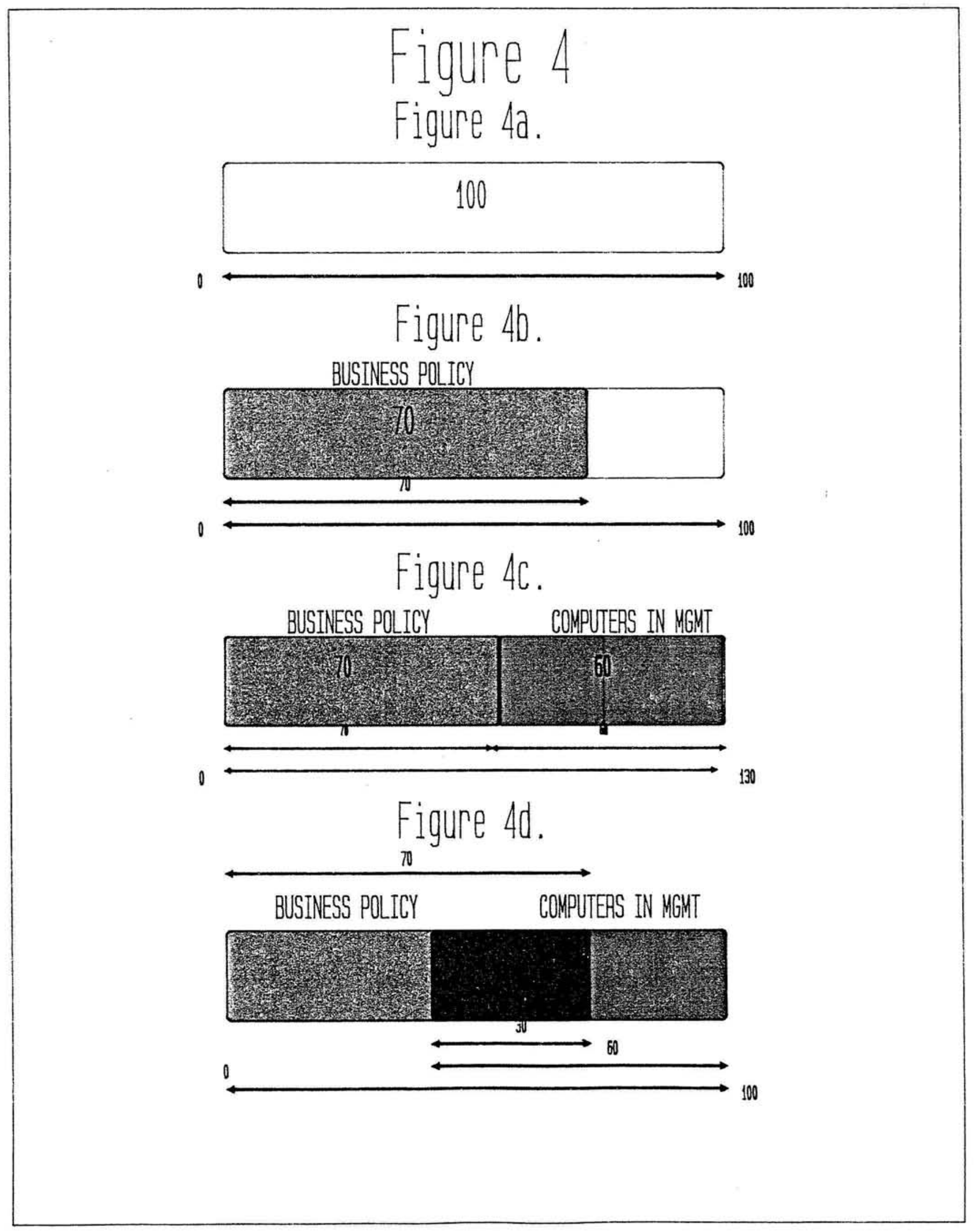


Figure 5

Figure 5 a.

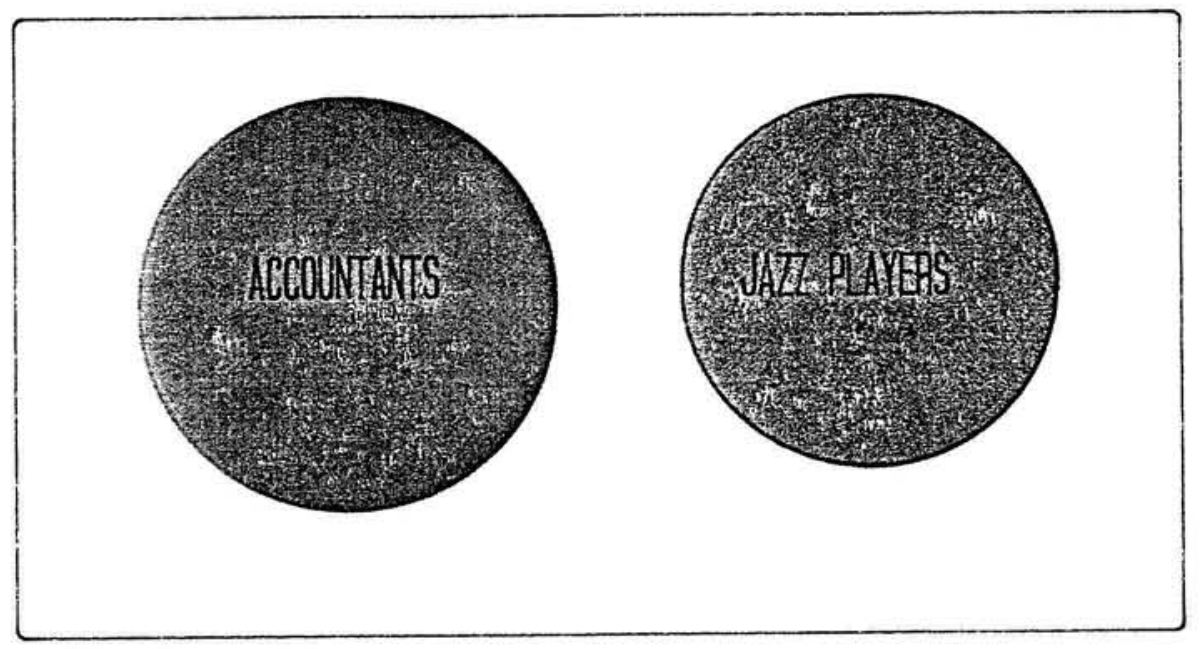

Figure $5 b$.

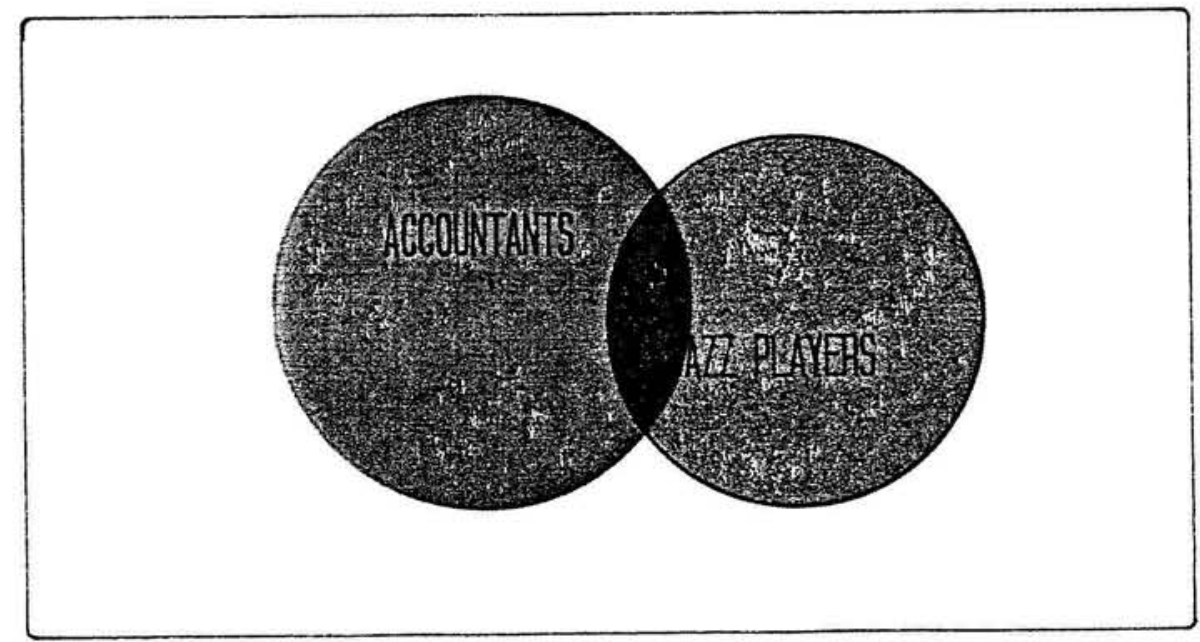

